\title{
Invited Discussion on: "What is the Evidence of Lymphoma in Patients with Prostheses Other Than Breast Implants?"
}

\author{
Alexandr A. Bessonov ${ }^{1} \cdot$ Mark W. Clemens ${ }^{2}$ (i)
}

Received: 20 January 2020/Accepted: 21 January 2020/Published online: 31 January 2020

(C) Springer Science+Business Media, LLC, part of Springer Nature and International Society of Aesthetic Plastic Surgery 2020

Level of Evidence $V$ This journal requires that authors assign a level of evidence to each article. For a full description of these Evidence-Based Medicine ratings, please refer to the Table of Contents or the online Instructions to Authors www.springer.com/00266.

Currently, there is no absolute consensus on the understanding of the etiology of breast implant-associated anaplastic large cell lymphoma (BIA-ALCL). Apart from the reported mechanisms associated with the exposure to the allogenic material of a textured surface breast implant-particulate matter absorption and allergic hypersensitivity reactions-there are multiple suggested triggers for unregulated $\mathrm{T}$ cell clonal expansion including mechanical trauma, aryl hydrocarbon toxin binding, and chronic inflammation induced by gram-negative bacterial wall lipopolysacharides. Any artificial device implantation is associated with tissue traumatization and initiation of inflammatory response and scar encapsulation. A complex cascade of cytokines causes leukocyte infiltration of the injury site with subsequent monocyte to macrophage differentiation [1]. There is not enough evidence yet to suggest a specific way of tissue traumatization or biofilmrelated inflammation that could be a unique feature associated with textured breast implants that could cause BIAALCL and differentiate textured implants from other implantable devices. However, there are numerous case reports and historic series containing potentially valuable

Mark W. Clemens

MWClemens@mdanderson.org

1 NMRC N.N. Petrov Research Institute of Oncology of the Ministry of Healthcare, St. Petersburg, Russia

2 Department of Plastic Surgery, MD Anderson Cancer Center, University of Texas, 1400 Pressler Street, Unit 1488, Houston, TX 77030, USA information that must be considered in light of the review by Dr. Ramos and colleagues.

\section{Lymphoproliferative Disorders of the Oral Cavity}

In 2012, Andrew Sciallis et al. performed a retrospective study of the CD-30-positive T cell lymphoproliferations of the head and neck [2]. Of the 14 ALK-negative patients, seven (50\% of the study population) had disease involving the oral cavity, mucosal surface of the lip or tongue. No patient had a known history of mucosal trauma and there are no data on the presence of dental implants. Authors concluded that considering primary mucosal CD30-positive $\mathrm{T}$ cell lymphoproliferations without systemic involvement as ALK-negative anaplastic large cell lymphomas (or other peripheral $\mathrm{T}$ cell lymphoma subtype) might lead to overtreatment and mischaracterization of more aggressive disease. Dental implants have become the most widely used type of installable prothesis with a very good safety profile. In 2015, Yoon described the first case of mucosal lymphoproliferative disorder in a 70-year-old woman. She presented with bleeding and swelling around mandibular and maxillary titanium dental implants that had been placed 8 years prior to manifestation of the symptoms. Severe bone loss around the implant could have been caused by functional overload and chronic inflammation. The patient's condition raised many possible diagnoses, including primary mucosal CD30 $+\mathrm{T}$ cell $\mathrm{LPD}$, mucosal involvement by cutaneous CD30 + T cell LPD or systemic ALCL, and traumatic ulcerative granuloma. The presence of the dental implants in the site of primary lesion formation allowed the authors to search for similarities with BIAALCL and compare their case with a previously reported orthopedic case of CD30+ ALK-negative $\mathrm{T}$ cell 
lymphoma in a patient with a tibial implant [3]. Since 2015 , there have been no other reports on mucosal lymphomas or LPDs associated with dental implants, despite the fact that according to the results of a survey, conducted by the American Association of the Oral and Maxillofacial surgeons, 500,000 people undergo dental implant procedures each year. This case report emphasizes that we must be cautious in placing overemphasis on the significance of rare single events which may be coincidental and not necessarily associative of implantable devices such as dental implants.

\section{Primary Bone T cell Lymphomas}

Primary bone lymphoma (PBL) is a rare primary extranodal lymphoma in the skeletal system that accounts for less than $1 \%$ of all lymphomas, about $4-5 \%$ of extranodal lymphomas, and about $3 \%$ of all malignant bone tumors $[4,5]$. Because of the extreme rareness of the condition, all the existing studies to the authors knowledge are retrospective and are spread in a long, to extremely long, analytical period. A retrospective study done at Memorial Sloan Kettering Cancer Center by Beal et al., identified 101 patients with histologically confirmed PBL from 1963 till 2003 and none had ALCL [6]. A retrospective study by Ramadan et al. identified 131 patients with primary bone lymphoma from the British Columbia Cancer Agency Lymphoid Cancer Database [7]. Among them were six patients with $\mathrm{T}$ cell lymphoma, 4 of them were diagnosed with ALCL. To the authors best knowledge, up until 2010 and ever since there has been no medical reports on cases of $\mathrm{T}$ cell lymphomas arising in the areas of orthopedic prothesis installment. However, in 2010, a case report by Bharath Palraj was published in the Journal of Foot and Ankle Surgery [3]. A case of a 77-year-old man presented with a 2-week history of pain and erythema at the medial aspect of the distal portion of his right leg, adjacent to an old wound where 7 years earlier he had undergone placement of a stainless steel plate and screws for repair of a spiral fracture of the tibia. During the operation "the surgeon encountered an amorphous gelatinous material deep in the soft tissues and adherent to the extracted metallic plate," which revealed malignant cells of $\mathrm{T}$ cell lineage and $\mathrm{CD} 30+$.

In 2016, Tuck et al. published a case report of a primary bone CD30+ ALK-negative ALCL [8]. A 50-year-old patient presented with symptoms similar to the ones described in the case published by Parlaj et al.: swelling, erythema and recurrent pain. Six months prior to that the patient had undergone rotator cuff repair and similar surgery at the same site 3 years earlier. He was taken to surgery for secondary interventions and debridement due to progression of what was considered osteomyelitis. Ten months after the initial surgery, enlarged supraclavicular nodes were detected. The patient was diagnosed with primary bone ALK-negative ALCL. This case is another reminder of the fact that primary bone lymphomas of $\mathrm{T}$ cell lineage, despite being very rare, do happen and are not associated with the presence of artificial implants. While there has been no BIA-ALCL case to date in a patient with solely smooth devices, one could imagine that sometime in the future a single case could coincidentally develop ALCL in a patient which happened to have smooth implants. A single event of disease should not be mistaken for causation, nor association which require formal epidemiological analysis and prospective data [9-11].

The link between malignancies and artificial constructions in orthopedic surgery has been addressed multiple times. There have been suggestions on possible association with bone sarcoma [12]. Eight cases of implant-related B cell lymphoma were reported in 2005 [13] and in 2016, Sunich et al. [14] published a case report of an 80-year-old female patient who developed Epstein-Barr negative DLBCL found in the peri-prosthetic membrane of a knee implant. The latter case has many similarities with the case described by Parlaj. According to the annual report of the American Academy of Orthopedic Surgeons and American Joint Replacement Registry published in 2018, there were $1,432,491$ total hip and knee arthroplasties performed in the USA [15]. Very low rates of primary bone lymphomas and T cell PBL in particular and anecdotal cases of boneimplant-related PBL do not justify the comparison with BIA-ALCL which is recognized as a separate entity and is now referred to as uncommon and emerging rather than "rare" due to an increasing number of confirmed cases. The BIA-ALCL PROFILE registry of the American Society of Plastic Surgeons now recognizes 288 confirmed or suspected cases in the US bringing the total worldwide cases to 871 as of December 6, 2019 [16].

\section{ALCL Arising After Bariatric Surgery}

Primary gastrointestinal lymphomas are predominantly B cell-type lymphomas. Primary gastric ALK-negative CD $30+$ ALCLs have been described in numerous case reports. In 2017, a case report by Manikkam Umakanthan et al. was published in the Journal of Clinical Oncology [17]. A 63-year-old patient with a history of chronic lymphocytic leukemia had undergone bariatric laparoscopic surgery with the installment of an adjustable gastric band (Lap-Band AP; Allergan, Dublin, Ireland). The main components of the device are the silicone elastomer band, access port and kink-resistant tubing. Approximately 2 years after her last treatment for leukemia and 6 years 
after Lap-Band implantation, a mass was noted in the epigastric region. After core biopsy CD30-positive ALKnegative ALCL was diagnosed. She underwent complete resection of the mass and removal of the band system. No systemic therapy was offered, yet the patient remained disease-free after 1 year post-op. The case shares multiple features with BIA-ALCL and comparison suggested by the authors of the report is justified. However, none of the known cases involved elastopolymers and silicone similar to those used in breast implant manufacturing.

\section{ALCL Arising in CTCL Patient}

Skin infiltration with malignant monoclonal $\mathrm{T}$ cell lymphocytes is the key feature characteristic of the Cutaneous $\mathrm{T}$ cell lymphomas (CTCLs). They resemble a heterogeneous group of extranodal non-Hodgkin's lymphomas that typically afflict adults, median age of 55-60 years. It is a rare disease with frequency of 1 in 100,000 of population. The Jak-3/STAT pathway has a role in fighting against CTCLs by promoting production of IL-5, IL-10, IL-17A, and IL-17F [18]. The same pathway is considered to be affected in the cases of BIA-ALCL.

Since the late 80 s, there have been several publications addressing transformation of CTCL into large cell lymphoma (LCL). The suspected mechanism of LCL is the progression of single malignant $\mathrm{T}$ cell clone. In a case report published by Engberg et al. in 2013, a 51-year-old man was initially diagnosed with non-specified $\mathrm{T}$ cell skin lymphoma [19]. He presented with erythematous, pruritic rash involving the face and torso, head and neck lymphadenopathy. Skin biopsy revealed lymphocytic infiltrate with CD2, CD3, CD4 and CD5 positive $\mathrm{T}$ cells. Four months after the end of chemotherapy, the patient noticed a solitary lesion located directly over the implanted port, a SlimPort MRI Ultra-Low Profile port (product \#0655640, Bard Access Systems, Salt Lake City, UT), that was used for injections throughout the entire course of treatment. The port contains a silicone catheter and polyurethane components. Skin biopsy revealed monoclonal CD30+ ALK-negative anaplastic large $\mathrm{T}$ cells. The mechanisms that trigger single $\mathrm{T}$ cell clone proliferation leading to ALCL formation might be the reason behind large-cell transformation (LCT) in the above-described case. LCT is considered a sign of poor prognosis at advanced stages of CTCL, and its appearance is characterized by drastic decreases in median overall survival. In the case report by Engberg, despite the appearance of large-cell transformation, local therapy only provided excellent control and survival benefit which is more common for BIA-ALCL which is characterized by local growth and a relatively indolent course. The presence of the foreign body itself or the materials used in implant manufacturing might be the triggering factor for $\mathrm{CD} 30+\mathrm{T}$ cells clonal progression.

The general absence of implant-associated cases of ALCL in cardiology, orthopedic surgery and dentistry with growing numbers of BIA-ALCL can indicate that the presence of chronic reaction to any foreign body cannot be considered an etiologic factor behind BIA-ALCL alone. We commend the authors for an important review while cautioning any conclusive assumptions. Unique properties of breast textured silicone implants such as particulate matter biodegradation should be closely studied as well as host properties of the patients developing BIA-ALCL, such as acquisition of genetic mutations and specific individual properties of immune response to determine how textured breast implants differ from other implantable devices.

\section{Compliance with Ethical Standards}

Conflict of interest The authors declare that they have no conflicts of interest to disclose.

Human and Animal Participants This article does not contain any studies with human participants or animals performed by any of the authors.

Informed Consent For this type of study informed consent is not required.

\section{References}

1. Johnston RB (1988) Jr Current concepts: immunology, monocytes and macrophages. N Engl J Med 318(12):747-752

2. Sciallis AP, Law ME, Inwards DJ, McClure RF, Macon WR, Kurtin PJ, Feldman AL et al (2012) Mucosal CD30-positive T-cell lymphoproliferations of the head and neck show a clinicopathologic spectrum similar to cutaneous CD30-positive T-cell lymphoproliferative disorders. Mod Pathol 25(7):983-992. https://doi.org/10.1038/modpathol.2012.38

3. Palraj B, Paturi A, Stone RG et al (2010) Soft tissue anaplastic large T-cell lymphoma associated with a metallic orthopedic implant: case report and review of the current literature. J Foot Ankle Surg 49:561-564

4. Unni KK, Hogendoorn PCW (2002) Malignant lymphoma. In: Fletcher CDM, Unni KK, Mertens F (eds) Pathology and genetics of tumours of soft tissue and bone. IARC Press, Lyon. World Health Organization Classification of Tumours

5. Desai S, Jambhekar NA, Soman CS, Advani SH (1991) Primary lymphoma of bone: a clinicopathologic study of 25 cases reported over 10 years. J Surg Oncol 46(4):265-269

6. Beal K, Allen L, Yahalom J (2006) Primary bone lymphoma: treatment results and prognostic factors with long-term follow-up of 82 patients. Cancer 106(12):2652-2656

7. Ramadan KM, Shenkier T, Sehn LH, Gascoyne RD (2007) Connors JM A clinicopathological retrospective study of 131 patients with primary bone lymphoma: a population-based study of successively treated cohorts from the British Columbia Cancer Agency. Ann Oncol 18(1):129-135

8. Tuck M, Lim J, Lucar J et al (2016) Anaplastic large cell lymphoma masquerading as osteomyelitis of the shoulder: an uncommon presentation. Case Reports bcr2016217317 
9. de Boer M, van Leeuwen FE, Hauptmann M (2018) Breast implants and the risk of anaplastic large-cell lymphoma in the Breast. JAMA Oncol 4(3):335-341. https://doi.org/10.1001/ jamaoncol.2017.4510

10. Coroneos CJ, Selber JC, Offodile AC, Butler CE, Clemens MW (2019) US FDA breast implant post-approval studies: long term outcomes in 99,993 patients. Ann Surg 269(1):30-36

11. Clemens MW, McGuire PA (2019) Discussion: a prospective approach to inform and treat 1340 patients at risk for BIA-ALCL. Plast Reconstr Surg 144(1):57-59

12. Keel SB, Jaffe KA, Petur Nielsen G, Rosenberg AE (2001) Orthopaedic implant-related sarcoma: a study of twelve cases. Mod Pathol 14:969-977

13. Cheuck W, Chan ACL, Chan JKC, Lau GT, Chan VN, Yiu HH (2005) Metallic implantassociated lymphoma: a distinct subgroup of large B-cell lymphoma related to pyothorax-associated lymphoma? Am J Surg Pathol 29(6):832-836

14. Sunitsch S, Gilg M, Kashofer K, Leithner A, Liegl-Atzwanger B, Beham-Schmid C (2016) Case report: Epstein-Barr-Virus negative diffuse large B-cell lymphoma detected in a peri-prosthetic membrane. Diagn Pathol 11:80

15. Annual Report of the American Academy of Orthopedic Surgeons and American Joint Replacement Registry (2018) Accessed online on January 10, 2020 at http://ajrr.net/images/annual_
reports/AAOS-AJRR-2018-Annual-Report-final.pdf?hsCtaTrack ing $=\mathrm{c} 794 \mathrm{~b} 145-8 \mathrm{~b} 50-405 \mathrm{a}-\mathrm{af5} \mathrm{c}-666 \mathrm{a} 0841 \mathrm{a} 730 \% 7 \mathrm{C} 6996 \mathrm{bb} 53-5 \mathrm{~b}$ 74-4d65-bb51-b24f37c55c9d

16. PSF PROFILE Registry Statistics. Available at: http://www. thepsf.org/PROFILE. Accessed 11 Dec 2019

17. Umakanthan JM, McBride CL, Greiner T, Yuan J, Sanmann J, Bierman PJ, Lunning MA, Bociek RG (2007) Bariatric implantAssociated anaplastic large-cell lymphoma. J Oncol Pract 13(12):838-839

18. Sibbesen NA, Kopp KL, Litvinov IV et al (2015) Jak3, STAT3, and STAT5 inhibit expression of miR-22, a novel tumor suppressor microRNA, in cutaneous T-Cell lymphoma. Oncotarget 6(24):20555-20569. https://doi.org/10.18632/oncotarget.4111

19. Engberg AK, Bunick CG, Subtil A, Ko CJ, Girardi M (2013) Development of a plaque infiltrated with large CD30+ T cells over a silicone-containing device in a patient with history of Sézary Syndrome. J Clin Oncol 31(6):e87-e89. https://doi.org/10. 1200/jco.2012.42.9241

Publisher's Note Springer Nature remains neutral with regard to jurisdictional claims in published maps and institutional affiliations. 